\title{
Commentary: Goals of surgical therapy in tricuspid valve endocarditis
}

\author{
Aaron J. Weiss, MD, and Anelechi C. Anyanwu, MD, FRCS
}

\author{
From the Department of Cardiovascular Surgery, Mount Sinai Medical Center, New York, NY. \\ Disclosures: Authors have nothing to disclose with regard to commercial support. \\ Received for publication Jan 7, 2019; accepted for publication Jan 7, 2019. \\ Address for reprints: Anelechi C. Anyanwu, MD, FRCS, Department of Cardiovascular Surgery, Mount Sinai \\ Medical Center, 1190 Fifth Ave, GP 2 West, Box 1028, New York, NY 10029 (E-mail: anelechi.anyanwu@ \\ mountsinai.org). \\ J Thorac Cardiovasc Surg 2019;157:1430-1 \\ $0022-5223 / \$ 36.00$ \\ Copyright (c) 2019 by The American Association for Thoracic Surgery \\ https://doi.org/10.1016/j.jtcvs.2019.01.021
}

The incidence of infective endocarditis is on the rise, and this condition remains associated with high rates of morbidity and mortality, despite advances in diagnosis and treatment. ${ }^{1}$ The worsening epidemic of intravenous drug abuse (IVDA) and the increasing rates of indwelling chronic venous lines and implantable cardiac devices have resulted in a recent surge of cases of tricuspid valve endocarditis. Right-sided infective endocarditis occurs far less frequently (5\%-10\% of total infective endocarditis cases) than does left-sided infective endocarditis, with most cases primarily affecting the tricuspid valve. Medical therapy with appropriately tailored antibiotics continues to be the dominant treatment of choice for tricuspid valve endocarditis, relegating surgical management to patients whose disease is refractory to medical treatment. More recent publications, however, demonstrate that increasing numbers of surgeries for tricuspid valve endocarditis are being performed. ${ }^{2}$ Although this is due in part to the rise in incidence of endocarditis, the increasing number of surgeries for tricuspid valve endocarditis may also reflect a more aggressive approach to surgical intervention.

Witten and colleagues ${ }^{3}$ from the Cleveland Clinic have adopted such an aggressive approach to the surgical treatment of endocarditis, and in this edition of the Journal, they report on one of one of the largest single-center experiences of surgery for right-sided infective endocarditis. Their results demonstrate outstanding outcomes, with an in-hospital mortality of $5.9 \%$ in 134 patients with surgically managed right-sided infective endocarditis, approximately half of whom had only right-sided infective endocarditis (the other half had coexisting left-sided infective endocarditis). Witten and colleagues ${ }^{3}$ highlight the principles of surgical management of right-sided endocarditis. They emphasize the need for early intervention before the onset of extensive tissue destruction; the need for complete removal of all infected tissue; and the prioritization of repair relative to replacement. In line with previously published data, ${ }^{4}$ their results demonstrate improved early morbidity vices long term).

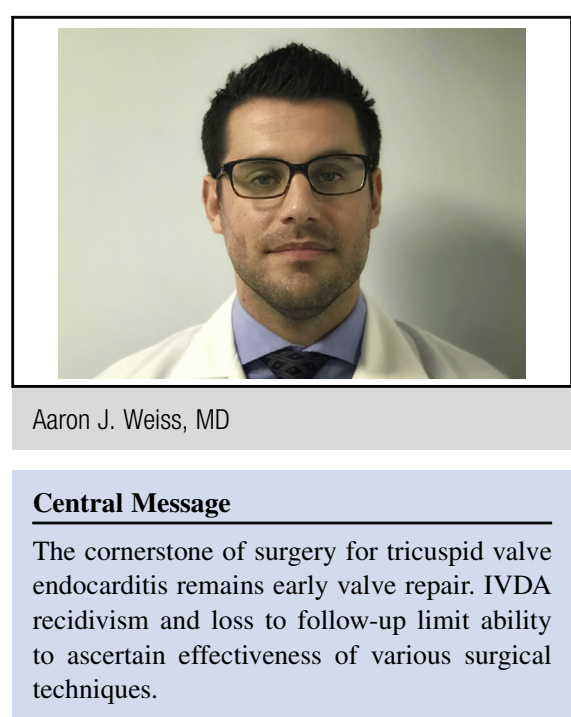

See Article page 1418 .

and mortality after tricuspid valve repair, compared with replacement, in endocarditis. Although residual moderate tricuspid regurgitation after repair may occur with an aggressive repair strategy, Witten and colleagues ${ }^{3}$ are very clear in their assertion that a less than perfect repair may be more favorable than prosthetic valve replacement in patients at higher risk of recurrent bacteremia (such as patients with intravenous drug abuse who are prone to recidivism or those who will continue to have intravenous catheters or de-

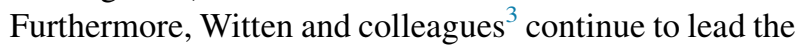
way with their standards of clinical data capture, reporting, and analysis by providing a thorough characterization of the predisposing conditions, surgical indications, underlying microbiology, and postoperative outcomes, as well as an attempt at long-term follow up, all of which help further our overall understanding of patient selection and optimal operative intervention for right-sided infective endocarditis. This seminal analysis should serve as an invaluable resource for surgeons dealing with tricuspid valve endocarditis, and it also sets a standard for future outcome studies on this subject. Despite the best efforts of Witten and colleagues, ${ }^{3}$ however, the long-term follow-up of these patients is far from complete or ideal, leaving many questions still unanswered. This paucity of complete and reliable longterm data after surgery for right-sided infective endocarditis 
is, however, an expected consequence of the patient population (particularly patients with IVDA, who have a higher rate of medical noncompliance, loss to follow-up, and social comorbidity) and also of several forms of bias that influence patient selection, treatment choices, medical management, and follow-up in this unique patient group. ${ }^{5}$ For this reason, the surgical focus and the evidence base to guide our practice rest primarily on the short-term control of infection and early survival. It remains difficult to assess reliably the long-term effectiveness of different surgical approaches. Furthermore, nonsurgical interventions aimed at preventing relapse and recidivism are a critical part of successful surgical therapy but historically have been inconsistently applied.

Hospitals and cardiac surgeons across the country will no doubt continue to see increasing rates of right- and leftsided infective endocarditis as the epidemic of opiate abuse and IVDA continues to ravage the nation. Witten and colleagues $^{3}$ remind us that the priorities of treatment are different for right-sided infective endocarditis, and as much as possible valve repair should be the default, even if that may carry the expectation of an imperfect hemodynamic result. Their excellent results also raise the question of whether regionalization of care for tricuspid valve endocarditis to hospitals with dedicated multidisciplinary teams (including primary care physicians, social workers, and drug addiction specialists) could yield better care and outcomes for this patient group.

\section{References}

1. Abegaz TM, Bhagavathula AS, Gebreyohannes EA, Mekonnen AB, Abebe TB Short- and long-term outcomes in infective endocarditis patients: a systematic review and meta-analysis. BMC Cardiovasc Disord. 2017;17:291. Erratum in: BMC Cardiovasc Disord. 2018;18:5.

2. Protos AN, Trivedi JR, Whited WM, Rogers MP, Owolabi U, Grubb KJ, et al Valvectomy versus replacement for the surgical treatment of tricuspid endocarditis. Ann Thorac Surg. 2018;106:664-9.

3. Witten J, Hussain ST, Shrestha NK, Gordon SM, Houghtaling PL, Bakaeen F, et al Surgical treatment of right-sided infective endocarditis. J Thorac Cardiovasc Surg. 2019;157:1418-27.e14.

4. Gaca JG, Sheng S, Daneshmand M, Rankin JS, Williams ML, O'Brien SM, et al Current outcomes for tricuspid valve infective endocarditis surgery in North America. Ann Thorac Surg. 2013;96:1374-81.

5. Anyanwu AC. The vagaries of patient selection in cardiovascular surgery. $J$ Thorac Cardiovasc Surg. 2016;152:842-6. 